thermodynamic parameters of ionic melts, such as activity coefficients. Evaluations were reported of excess functions for the enthalpy and changes in volume on mixing ionic melts of the same or of different valency structure. As a result, some of the current quantitative theories that have been developed for non-ionic liquid mixtures can begin to be adapted to ionic melts. Considerable advances may be expected in the next few years in this branch of the theory of liquids.

One-third of the papers presented dealt with transport properties of ionic melts, which have been studied for a number of years and which continue to receive much attention. Use of radioisotopes has greatly enriched the possibilities of making measurements on diffusion, the correlation of which with other transport phenomena helps to unravel complicated structural problems. In addition to their technological importance, transport properties can yield tests of theoretical models for ionic melts that can be much more sensitive than equilibrium properties to structural details assumed in the model. Discussion of measurements of thermo-electric power of ionic melts suggested further interesting possibilities that seem likely to attract additional attention in the years ahead.

A. R. UвBELOHDE

\title{
WOOD EXTRACTIVES
}

$\mathrm{A}$ SYMPOSIUM on wood extractives was arranged by the Plant Phenolics Group and held at the Royal Holloway College, Englefield Green, Surrey, during September 20-22. The meeting proved valuable in bringing together workers in different fields, including several from overseas, having a common interest in the minor or extraneous components of woods. After an introductory session the subject of wood extractives was dealt with under three headings, namely biosynthesis and taxonomy, the chemistry of extractives, and their influence on utilization of wood and wood products.

Dr. F. E. King (British Petroleum Co., Itd.) opened the symposium with an introductory address entitled "Perspectives in the Chemistry of Wood Extractives". Dr. King surveyed the historical development of investigations on extractives, commencing with those of technical interest such as the tannins, dyestuffs and resins, and proceeding to the work of Erdtman on the heartwood components of coniferous trees and his own work on the corresponding components of hardwoods. These investigations led to the conception of heartwood components as 'taxonomic tracers' which can be used to supplement the observations on morphological features employed by botanists in the taxonomic classification of trees. Dr. King emphasized the wide variety of $\mathrm{C}_{6}-\mathrm{C}_{3}-\mathrm{C}_{6}$ compounds that are found in woods and discussed a fow unusual structures that have been encountered.

In the second paper, given by Prof. F. W. Jane (Royal Holloway College), an account was given of the structure of the tree and the distribution of the various tissues in it. This was helpful to the audience, consisting predominantly of chemists. The extraneous substances are classified by botanists as gums, resins, tannins, oils, mucilages, colouring matters, mineral deposits, etc., and the location of these in the structure was described and illustrated. There is clearly room for closer co-ordination between the observations of botanists, based largely on the microscopic staining reactions of these components, and their investigation by chemists.

Prof. E. J. Bourne (Royal Holloway College) described some new methods for the characterization and separation of extractives that have been studied in his laboratory. These include the use of molybdates and tungstates which form com. plexes with polyhydroxy compounds and can assist in their separation by electrophoresis, the addition of phenylboronic acid to the solvents used in paper chromatographic separations of these com- pounds, the use of boron trichloride under very mild conditions to identify families of extractives by removing substituent groups, and the fractionation of mixtures by means of a new liquid/liquid countercurrent extraction technique, which was demonstrated.

The session on biosynthesis and taxonomy opened with a paper by Prof. W. Sandermann (Bundesforschungsanstalt für Forst- und Holzwirtschaft, Reinbek, West Germany) on the biogenesis of terpenes in plants. Prof. Sandermann discussed the part played by mevalonic acid and its conversion into geranyl and farnesyl pyrophosphates, from which the more complex terpenes may be derived. He then described his work on the incorporation of labelled precursors in plants and showed how a distinction between alternative mechanisms can be made by these methods; for example, the biosynthesis of $\alpha$-pinene and thujone was shown to take place by an electrophilic substitution rather than by an addition mechanism. A series of terpenoid compounds has been found in teak and correlated structurally with the anthraquinones present in this wood.

The systematic distribution of phenolic substances in plants was discussed by Dr. E. C. Bate-Smith and Dr. T. Swain (Low Temperature Research Station, Cambridge) in a paper presented by Dr. Swain. The contribution that a study of the chemical components of plants can make to taxonomic classification was emphasized. One of the results of an extensive survey of the occurrence of the common phenolics is the recognition that plants in some families or higher groupings are devoid of the capability of synthesizing certain types of compound. In this connexion the occurrence of compounds containing vicinal trihydroxy groups and of ellagic acid in members of the Rosaceae was discussed.

In continuation of this theme Prof. C. W. L. Bevan (University College, Ibadan, Nigeria) presented a paper entitled "Wood Extractives as Tracer Substances in Taxonomy", and referred particularly to the results of a survey carried out in his Depart. ment of components of woods of the family Meliaceae. He also outlined the procedures followed in determining the structures of gedunin, isolated from Entandrophragma angolense and of khivorin from Khaya ivorensis and $K$. grandifoliola.

In the session on the chemistry of wood extractives four papers were presented, dealing respectively with the lignans, tropolones, stilbenes, and flavonoids, these being the principal types of phenolic compounds 
that are found in wood. In discussing the lignans Prof. R. D. Haworth (University of Sheffield) pointed out that the basic structure common to all lignans comprises two phenylpropane units linked in the $\beta$-positions. The structure and stereochemistry of some of the naturally occurring lignans, of which about forty are known, was considered. Where ring closure has occurred, with formation of phenyltetralin or furano-structures, the creation of a new asymmetric carbon atom renders the stereochemistry complex. There is evidence that the lignan structure can be formed by oxidation of $\alpha \beta$-unsaturated phenylpropane compounds, such as ferulic acid.

A survey of the discovery and determination of structure of the tropolones found in various woods was given by Prof. J. Gripenberg (Institute of Technology, Helsinki, Finland). The distribution of the tropolones, which appear to be confined to the family Cupressaceae, was discussed and their general properties and synthesis described. It is interesting to note that all the nine known tropolones occurring in wood contain an isopropyl (or isopropenyl) group and appear to be closely related to the terpenes. A scheme by which they may be derived from carone has been proposed by Erdtman.

Dr. D. E. Hathway (British Leather Manufacturers' Research Association) discussed the occurrence of stilbenes in wood and referred to the recorded incidence of hydroxystilbenes in conifers and dicotyledonous trees. In a study of the extractives of the heartwood of Eucalyptus wandoo, $3: 5: 4^{\prime}$-trihydroxy. stilbene and its 3 -glucoside were found to be present, and these compounds have been used as tracer substances in an investigation of the heartwoods of 60 species belonging to the Longiores sub-section of the genus Eucalyptus. This method confirms the existence of certain anomalies in the classification that have been suspected on other grounds.

The fourth paper in this group, dealing with the flavonoids, was prepared by Dr. R. A. Laidlaw and Dr. J. W. W. Morgan (Forest Products Research Laboratory). After a short account of the occurrence, function and nature of the flavonoids of wood, Dr.
Laidlaw went on to consider three classes of these compounds, namely the leucoanthocyanidins, dihydroflavonols and benzylcoumaranones, in greater detail. Methods for determination of the structure and stereochemistry of the leucoanthocyanidins and their characterization as flavan-3:4-diols were discussed. Among the dihydroflavonols, dihydromorin, phellamuretin and keyakinol were selected for special mention. The naturally occurring aurones and hydroxybenzylcoumaranones were described and the behaviour of maesopsin (tetrahydroxybenzylcoumaran-3-one) on heating with alkali was discussed in detail.

The final section of the symposium consisted of two papers in which different aspects of the utilization of wood were considered. Dr. R. H. Farmer (Forest Products Research Laboratory) discussed the influence of extractives present in different timbers on some of their technically important properties and applications. A brief account was given of the manner in which the colours of woods (and the changes in colour occurring under certain conditions) and their natural durability are related to the chemical nature of the extractives present in them. Examples were then given of interaction between wood components and other materials with which the wood comes into contact. These include the inhibition of the hardening of unsaturated polyester resins by certain timbers, shown to be due generally to quinones or hydroxystilbenes, and the retardation of setting of cement by water-soluble sugars and tannins.

In the final paper Prof. B. Lindberg (Swedish Forest Products Research Laboratory) described the influence of extractives on the pulping of timber. Extractives can influence the sulphite or the alkaline pulping processes in various ways. Thus they may render the penetration of the cooking liquor into the wood more difficult, react with the cooking liquors and modify them, or condense with the lignin, preventing its dissolution. Resinous and fatty components may give rise to 'pitch troubles', and can cause difficulty in bleaching because chlorination. renders them more lipophilic. R. H. FARMER

\section{THE INTERNATIONAL SCIENTIFIC FILM ASSOCIATION}

\section{FIFTEENTH CONGRESS}

$\mathrm{T}$ HE fifteenth annual congress of the International Scientific Film Association was held at Rabat, Morocco, during September 14-20, 1961. This was the first time that the Association had met outside Europe. The congress was under the patronage of H.R.H. Prince Moulay Abdullah.

Of the Association's twenty-five member countries, sixteen sent delegates and there were also observers from Guinea, India, Indonesia, the Lebanon and Mali. The largest delegation of twenty-two people was from Great Britain, followed by the U.S.S.R. with about twenty.

All delegates, observers and friends enjoyed the gracious Moroccan hospitality. From Rabat, where all were well housed in the new Cité Universitaire, excursions were made to Casablanca, Fes, Meknes and Marrakech. As the sun shone without hesitation throughout each day on every day, expeditions were also organized to the delightful beach at Temarah.
In his address of welcome, M. Moulay Ahmed Alaoui, Minister of Information, Fine Arts and Tourism, expressed his country's pleasure at the honour being paid to Moroceo as the scene of the congress. This indicated also the importance of the African continent in the building up of the modern world. For countries like Morocco, the cinema was not a diversion, but an important instrument in education and instruction.

This congress has always two aspects: one organizational, the other concerned with the problems of scientific film makers. The former provides the machinery whereby the film makers can get together: and see and discuss films in three main sections: research, education and popular science. For some time there has been a feeling that the organization has needed tightening, and this congress took certain steps to do so. The new president is Mr. Edgar Anstey (Great Britain), who replaces Mr. Alexandre 